\title{
The Effects of Foreign Language Learning on Creativity
}

\author{
Behzad Ghonsooly \\ English Department, Ferdowsi University of Mashhad \\ PO box 91779-48974, Park Square, Ferdowsi University Mashhad, Iran \\ E-mail: Ghonsooly@yahoo.com \\ Sara Showqi (Corresponding author) \\ English department, Ferdowsi University of Mashhad \\ PO box 91779-48974, Park Square, Ferdowsi University Mashhad, Iran \\ E-mail: s.showqi@gmail.com
}

Received: January 11, 2012

Accepted: January 21, 2012

Published: April 1, 2012

doi:10.5539/elt.v5n4p161

URL: http://dx.doi.org/10.5539/elt.v5n4p161

\begin{abstract}
The present study investigates the possible influence of foreign language learning on individuals' divergent thinking abilities. Unlike the large body of research devoted to unfolding the effect of bilingualism on cognitive functions, foreign language learning has gained little attention. This study aimed at bringing into attention the distinctive nature of foreign language learning which deserves a separate line of investigation. To this end, controlling age, gender, socioeconomic status, and previous learning experiences, the performance of advanced learners of English as a foreign language (EFL) and non-EFL learner monolinguals were compared on the Torrance Test of Creative Thinking. The findings revealed that learning English as a foreign language to an advanced level significantly enhances all four divergent thinking abilities, i.e., fluency, elaboration, originality and flexibility. Such enhancement can be attributed to specific cognitive practices that language learning brings, and the psychological consequences of being trained under a system different from school system.
\end{abstract}

Keywords: Creativity, Divergent thinking, Foreign language learning, Monolingualism

\section{Introduction}

Creativity comprises an important dimension of cognition and ample attempts have been made to unravel its underlying processes and functions. Although Goltan (1869) was the first to introduce creativity, however, this concept was mainly brought to attention by the efforts of Guilford (1950) and Torrance (1962) who are considered as the key figures that made creativity studies scientific. They approached creativity from a psychometric perspective to make its assessment possible. Many researchers have tried to provide a comprehensive definition of creativity but this is too vast a concept to be shortly defined. For instance, Smith (1998) refers to it as the capacity to generate ideas, possibilities, and alternatives. Sternberg and Lubart (1995) suggest that creativity can be defined as the ability to produce work that is novel and adaptive with regard to task or situational limitations.

A number of studies have focused on the relation between creativity and intelligence. Michalko (1998) regards creative thinking as distinct from intelligence. That is neither high level of intelligence guarantee creativity, nor does creativity represent intelligence. Srinivasan (2006) also confirms the low correlation between intelligence and creativity; however, he asserts that some forms of intelligence such as fluid intelligence may play a significant role in creativity. There are also some counterclaims; Silvia (2008), for instance, reanalyzed the previous data through advanced methodologies. It was found that intelligence could be strongly predicted by two components of creativity: originality and fluency (cited in Hennessey \& Amabile, 2009). Nevertheless, many researchers such as Runco (2007) believe in threshold theory that considers a minimum level of intelligence to be necessary and below which creativity is rarely observed.

Bilingualism has devoted one out of multiple dimensions of creativity research to itself. A large number of researchers have engaged in seeking the relationship between creativity and bilingualism. Ricciardelli (1992) conducted a meta-analysis of 24 studies that examined this relation. Despite some incongruities observed among them, the general inclination was toward the superiority of bilinguals to monolinguals in performance on measures 
of creativity. Furthermore, he asserted that most studies were conducted on children and employed measures of divergent thinking to assess creativity. Hommel, Colzato, Fischer, and Christoffels (2011) affirmed the positive impact of bilingualism on creativity, positing that it is the underlying processes and mechanisms of creativity that are influenced by bilingual practice not the unitary concept per se.

As discussed earlier creativity is enhanced by cognitive functions, so it can be expected that developments in bilinguals' cognitive functions facilitate creative abilities. To compensate for the scarcity of creativity research on adult bilinguals, Kharkhurin conducted a series of studies on creativity among adult bilinguals. Khakhurin (2007) considered cross-linguistic factors such as bilinguals' proficiency in both languages and the age of acquisition, as well as cross-cultural factors such as the experience of bicultural interactions, affect their cognitive development. Bilinguals' experience of participation in two cultures makes them see the world through two different conceptual systems. These enhanced conceptual representations may enhance cognitive flexibility, divergent thinking, and creative expression of experiences (Cummins \& Gulutsan, 1970; Okoh, 1980; cited in Kharkhurin, 2007).

Kharkhurin (2008) found that Russian-English bilingual immigrants in the U.S. showed superiority in fluency aspect of divergent thinking. He further analyzed the same sample and noticed advantage in nonverbal creativity for bilinguals (2010b). In another study, Kharkhurin (2009) compared Farsi-English bilinguals living of U.A.E. with their monolingual peers living in Iran and found greater performance in measure of originality and fluid intelligence for bilinguals. However, these and similar studies in the field suffer from a serious drawback which is ignoring the bilinguals' developmental factors such as the age of L2 acquisition, the conditions under which the L2 was acquired, the degree of proficiency in L2 (Lemmon, \& Goggin, 1989, cited in Kharkhurin, 2011).

Birman, Trickett, and vinokurov (2002) believed that "language acquisition is often accompanied by adoption of the cultural values of the country in which this language is acquired". On the other hand, creativity researchers as Lubart (1999) and Niu and Sternberg (2001) drew on the significant effect of social, economic, political, and cultural factors on creative potentials (cited in Kharkhurin, 2010b, p. 776). To verify the effect of sociocultural environment on the creativity of bilinguals, Kharkhurin $(2010 \mathrm{~b})$ chose four groups of monolingual and bilinguals from two distinctive sociocultural environments. The findings suggested that the performance of bilinguals and monolinguals on divergent thinking measures varied in each sociocultural environment. Sternberg (2006) pointed out that creativity is a decision that can be made by anyone but most people do not make because they are afraid of its costs. He noted that providing rewards and minimizing the costs would encourage a more creative spirit in the society.

As mentioned earlier, bilingualism has devoted a noticeable body of creativity research to itself. Many studies assert the positive effect of bilingualism on creativity but few studies have investigated the impact of learning a foreign language in a context where the interaction is limited to teacher-student form not everyday social interactions. To the knowledge of the present researchers, there has been just one study conducted on the effect of foreign language learning on creativity by Landry (1974). He chose his sample from two types of elementary schools, where one had a foreign language learning program but the other did not. From each school the first, fourth, and sixth graders were chosen to include assessing the effect of proficiency on creativity, too. Controlling for socioeconomic status of the students, Torrance Test of Creativity (1966) was employed to measure creativity. The results indicated the superiority of fourth and sixth graders who had learned a foreign language at school. However, no significant difference was found between first graders in either school. That is, knowledge of the language should reach a threshold to enhance cognition. This finding is in line with Cummins' (1976) who claimed bilinguals should reach a high level of proficiency for the improvement in cognitive functions to occur. Furthermore, he argues that since divergent thinking requires divergence from old traditions and openness to new experiences, the practice of foreign language learning can provide a valuable enriched experience to cognitive developments. Witnessing a gap, the researchers felt the unique contribution that foreign language learning can make to cognitive improvements has been overlooked.

\section{Methodology}

\subsection{Participants}

This study aimed at comparing the performance of advanced learners of English as a foreign language and their early beginner counterparts on a measure of divergent thinking ability. A sample of 60 advanced English learners aged 16 to 18 (Mean=17, SD=1.04) who have been studying English for at least six consecutive years, and 60 monolinguals in the same age range (Mean $=16.4, \mathrm{SD}=0.6$ ) were selected. The participants were all female and took part in the research project voluntarily.

\subsection{Materials}

\subsubsection{Background Questionnaire}

Since creativity is under the influence of sociocultural and socioeconomic status, this questionnaire was designed by 
the researchers to assert their monolingualism, control previous learning experiences, recreational activities, family background and socioeconomic status.

\subsubsection{Raven's Progressive Matrices}

It is a measure of general nonverbal intelligence and is used in to make sure participants are at a similar intellectual level. The booklet comprises five sets (A to E) of 12 items each (e.g., A1 through A12), with items within a set becoming increasingly difficult, requiring ever greater cognitive capacity to encode and analyze information. All items are presented in black ink on a white background.

\subsubsection{Torrance Test of Creative Thinking (TTCT)}

Torrance Test of Creative Thinking (1974) is known as the most widely used measure of creativity and has been translated to more than 35 languages across the world. It is comprised of four scales: fluency (the number of ideas and solutions), originality (the rarity of ideas), elaboration (the number of added ideas, and the ability to develop and elaborate on ideas), and flexibility (the number of different categories of relevant responses being used) (Craft, 2001; Hommel, Colzato, Fischer, \& Christoffels, 2011; Villalba, 2008). Since half of the participants did not have English knowledge the Persian translation of this test was used. The validity and reliability of the Persian version has been confirmed for the context of Iran by Abedi (1993).

Since creativity is influenced by IQ, sociocultural and socioeconomic status, after considering the data gained from the first two questionnaires, a number of participants were excluded and the rest 120 participants were measured on TTCT.

\section{Results and Discussion}

To exclude the possible effects of IQ on performance in measures of divergent thinking, the participants were chosen on the basis of their IQ. That is, the monolinguals $(\mathrm{M}=124.7, \mathrm{SD}=6.33)$ and the advanced foreign language learners $(\mathrm{M}=123, \mathrm{SD}=9)$ were in the same range of IQ $(122-127)$. To determine if there was a significant difference in Torrance Test of Creative Thinking between monolinguals and advanced foreign language learners (AFLL), four independent samples t-tests were carried out. TTCT consists of four subscales, including fluency, elaboration, originality, and flexibility. As shown in table (1), the t-test on creativity revealed that:

The AFLLs $(M=31.5, S D=5.04)$ outperformed the monolinguals $(M=27.5, S D=5.71), t(118)=4, p<0.01$, on the TTCT measure of fluency;

The AFLLs $(\mathrm{M}=13.35, \mathrm{SD}=3.21)$ also outperformed monolinguals $(\mathrm{M}=11.16, \mathrm{SD}=3.58), \mathrm{t}(118)=3.517, \mathrm{p}<0.01$, on the measure of elaboration;

The AFLLs $(\mathrm{M}=21.6, \mathrm{SD}=4)$ outperformed monolinguals $(\mathrm{M}=17.5, \mathrm{SD}=4.64), \mathrm{t}(118)=5.17, \mathrm{p}<0.01$, on the measure of originality;

And finally, the AFLLs $(M=16.82, S D=2.32)$, outperformed the monolinguals $(M=14.9, S D=2.64), t(118)=4.26$, $\mathrm{p}<0.01$, on the measure of flexibility.

To assert the magnitude of the difference in the means, the effect size $\left({ }^{2}\right)$ was calculated for each subscale: fluency (0.11), elaboration (0.09), flexibility (0.13), and originality (0.18). According to Dornyei (2007) the effects offered by the eta squared can be categorized in three ways: $0.01=$ small effect, $0.06=$ moderate effect and $0.14=$ large effect. Given that, the effect sizes calculated in this study were large for fluency, originality, and flexibility and above moderate for elaboration, confirming the significant difference between the AFLLs and monolinguals on all four subscales of TTCT (table 1). In addition to independent samples t-test, an ANOVA was performed with four measures of divergent thinking as dependent variables and language group as independent variable (tables $2 \mathrm{a}, 2 \mathrm{~b}, 2 \mathrm{c}$, $2 \mathrm{~d})$. The results confirmed that the advanced foreign language learners significantly outperformed monolinguals in all four measures.

The remarkable superiority of advanced foreign language learners to monolinguals on measures of divergent thinking can be attributed to several reasons. This study imposed rigid selection criteria. The participants belonged to families of a similar range of socio-economic status, they were all Persian monolinguals, they had the same IQ level, they were not under the influence of any learning experiences except for those offered at school, and none of them came from broken homes. Attempts to control these factors made us claim that the participants had everything in common but the experience of learning a foreign language in language institutes.

Foreign language learning can affect learners in two ways. The first one is the cognitive practices that are imposed to brain by learning another language. Bialystok (2007) mentioned that bilinguals are constantly dealing with two language systems that are simultaneously active and interacting all the time. In order for bilinguals to communicate efficiently and manage two languages at their disposal effectively, they need to control their attention to the required 
system and inhibit the interference of the other language system which is not used at the same time. Bialystok and Martin (2004), stressing the necessity of inhibiting the unused language system, claim that early bilingualism fosters children's ability to control attention. Although learning a foreign language does not entail intense mental practices that are required in a bilingual context, mastering it in a classroom context may impose even more noticeable changes and developments through the burdensome practice that the learners take charge of. Landry (1974) emphasizing that a major characteristic of divergent thinking is willingness and adoptability to change, he attributed improvements in creativity among foreign language learners to the willingness and motivation that is shaped in them to change and adapt themselves to this new experience.

The second cause of this enhancement can be ascribed to the new environment, where in addition to a new linguistic system learners get familiar with cultures, customs, and beliefs distinctive from their own, and hence their old attitudes face challenge and they are forced to view the world from various perspectives. Familiarity with two cultures makes them see the world through two different conceptual systems. These boosted conceptual representations may enhance cognitive flexibility, divergent thinking, and creative expression of experiences (Cummins \& Gulutsan, 1970; Okoh, 1980; cited in Kharkhurin, 2007). Furthermore, different nuances in the conception of common cultural issues among bilinguals make them more flexible in the face of ambiguities, enhancing their "tolerance of ambiguity" which is a peculiarity of divergent thinking. Moreover, as Lubart (1999) asserts bilinguals, experiencing two distinctive linguistic and conceptual systems, establish distinct associations to the same concept and relate irrelevant concepts from different categories. This feature is fundamental to divergent thinking (cited in Kharkhurin, 2007).

Another factor to be considered is the diverse atmospheres that exist in language institutes and schools. According to Mower-Reynolds (2005) fostering creativity is not regarded as a main goal to most educational systems and teachers prefer convergence rather than divergence on the part of students, so that they can more easily cover the heavy load of course materials. Mower-Reynolds (2005) referred to Torrance (1963) who found "behaviors of creative students, such as being playful, emotional, open, critical of others, and stubborn, are discouraged and thought to be disruptive to the existing organization" (p. 1) and Guncer and Oral (1993) who indicated that teachers conceived of creative students as "non-conformists" (p. 1) and this conception may negatively influence students academic performance. So as Sternberg (2006) pointed out that creativity is a decision that can be made by anyone but most people do not make because they are afraid of its costs. He suggested that providing rewards and minimizing the costs would encourage a more creative spirit in the society. However, language institutes take a more informal approach to learning, encourage students to participate in various discussions and activities held in the class, and welcome opposing ideas. Furthermore, because there are fewer students in each class in language institutes as opposed to schools, each student receives a higher level of attention and appreciation, and individuality.

\section{Conclusion}

Creativity has been under scientific investigations for more than half a century and it is still at the peak of attention. Lately, a number of researchers have engaged in unfolding the relation between bilingualism and creativity and have found significant associations between them. On one hand, bilingualism enhances cognitive functions such as planning, cognitive flexibility and working memory; on the other hand, creativity is heavily dependent on the strength and power of these functions. Therefore, the more vastly the cognitive functions are improved, the greater levels of creativity will be attained. However, learning a foreign language in the context of classroom would definitely have some consequences distinguishable from bilingualism. The present study found that mastering a foreign language in a classroom context dramatically increases the four components of divergent thinking ability, i.e., fluency, elaboration, originality, and flexibility. This asset can be ascribed to the cognitive developments that might have been brought by this experience (needs to be investigated) as is caused by bilingualism, or the intensive training offered in an atmosphere that is different from those experienced at school or home. In such atmosphere creative abilities can be fostered through practicing flexibility to openly face novelties; this happens as students get familiar with new linguistic system, new cultures and customs, and organization of different conceptual presentations. This study measured divergent thinking abilities merely among females; it is suggested to conduct a series of research in different sociocultural environments, assessing divergent thinking abilities in both genders, to have a better understanding of language learning and creativity.

\section{References}

Abedi, J. (2002). A latent-Variable modeling approach to assessing reliability and validity of a creativity instrument. Creativity Research Journal, 14(2), 267-276.

Birman, D., Trickett, E. J., \& Vinokurov, A. (2002). Acculturation and adaptation of Soviet Jewish refugee adolescents: Predictors of adjustment across life domains. American Journal of Community Psychology, 30(5), 
585-607.

Cummins, J. (1976). The influence of bilingualism on cognitive growth: A synthesis of research findings and explanatory hypothesis. Working Papers on Bilingualism, 9, 1-43.

Cummins, J., \& Gulutsan, M. (1974). Some effects of bilingualism on cognitive functioning. In Carey, S. T. (ed.), Bilingualism, biculturalism and education. Edmonton: University of Alberta.

Galton, F. (1869). Hereditary Genius: an inquiry into its laws and consequences. Macmillan, London.

Guilford, J. P. (1950). Creativity. American Psychologist, 5, 444-454.

Hennessey, B. A., \& Amabile, T. M. (2010). Creativity. Annu. Rev. Psychol., 61, 569-98. http://dx.doi.org/10.1146/annurev.psych.093008.100416

Hommel, B., Colzato, L., S., Fischer, R., \& Christoffels I., K. (2011). bilingualism and creativity: benefits in convergent thinking come with losses in divergent thinking. Frontiers in psychology, 2, 1-5. http://dx.doi.org/10.3389/fpsyg.2011.00273

Kharkhurin, A. V. (2007). The role of cross-linguistic and cross-cultural experiences in bilinguals' divergent thinking. In I. Kecskes \& L. Albertazzi (Eds.), Cognitive aspects of bilingualism (pp. 175-210). Dordrecht, the Netherlands: Springer.

Kharkhurin, A. V. (2008). The effect of linguistic proficiency, age of second language acquisition, and length of exposure to a new cultural environment on bilinguals' divergent thinking. Bilingualism: Language and Cognition, 11, 225-243.

Kharkhurin, A. V. (2009). The role of bilingualism in creative performance on divergent thinking and Invented Alien Creatures tests. Journal of Creative Behavior, 43, 59-71.

Kharkhurin, A. V. (2010a). Bilingual verbal and nonverbal creativenbehavior. International Journal of Bilingualism, 14, 1-16. http://dx.doi.org/10.1177/1367006910363060

Kharkhurin, A. V. (2010b). Sociocultural differences in the relationship between bilingualism and creative potential. Journal of Cross-Cultural Psychology, 41, 776-783. http://dx.doi.org/10.1177/0022022110361777

Kharkhurin, A. V. (2011). the role of selective attention in bilingual creativity. Creativity research journal, 23(3), 239-254. http://dx.doi.org/10.1080/10400419.2011.595979

Landry, R. J. (1974). A comparison of second language learners and monoloniguals on divergent thinking tasks at the elementary school level. The modern language journal, 58(1), 10-15.

Lemmon, C. R., \& Goggin, J. P. (1989). The measurement of bilingualism and its relationship to cognitive ability. Applied Psycholinguistics, 10, 133-155.

Lubart, T. I. (1999). Creativity across cultures. In R. J. Sternberg (Ed.), Handbook of creativity (pp. 339-350). New York: Cambridge University Press.

Michalko, M. (1998). Thinking like a genius: Eight strategies used by the supercreative, from Aristotle and Leonardo to Einstein and Edison. The Futurist, 32(4), 21.

Niu, W., \& Sternberg, R. J. (2001). Cultural influences on artistic creativity and its evaluation. International Journal of Psychology, 36(4), 225-241.

Okoh, N. (1980). Bilingualism and divergent thinking among Nigerian and Welsh school children. Journal of Social Psychology, 110, 163-170.

Ricciardelli, L. A. (1992). Creativity and bilingualism. Journal of Creative Behavior, 26, 242-254.

Runco, M. A. (2007). Creativity. Theories and Themes: Research, Development, and Practice. San Diego, CA: Academic Press.

Silvia, P. J. (2008). Creativity and intelligence revisited: a latent variable analysis of Wallach and Kogan (1965). Creat. Res. J., 20, 34-39.

Srinivasan, N. (2007). Cognitive neuroscience of creativity: EEG based approaches. Methods, 42, 109-116. http://dx.doi.org/10.1016/j.ymeth.2006.12.008

Sternberg, R. J. (2006). The nature of creativity, Creativity Research Journal, 18(1), 87-98.

Sternberg, R. J., \& Lubart, T. I. (1995). Defying the crowd: Cultivating creativity in a culture of conformity. New York: Free Press. 
Torrance, E. P. (1962). Guiding creative talent. Englewood Cliffs, NJ: Prentice Hall.

Table 1. Independent samples t-test of advanced foreign language learners' and monolinguals' performance on fluency, elaboration, originality, and flexibility measures of creativity.

\begin{tabular}{lcccccc}
\hline & M & SD & D & T & sig & Effect size ( ${ }^{2}$ ) \\
\hline Fluency & & & 118 & 4 & 0.000 & 0.11 \\
Advanced & 31.49 & 5.04 & & & & \\
Monolingual & 27.55 & 5.71 & & & & \\
Elaboration & & & 118 & 3.51 & 0.001 & 0.09 \\
Advanced & 13.35 & 3.21 & & & & \\
Monolingual & 11.16 & 3.58 & & & & \\
Originality & & & 118 & 5.17 & 0.000 & 0.13 \\
Advanced & 21.59 & 3.97 & & & & \\
Monolingual & 17.51 & 4.64 & & & & \\
Flexibility & & & 118 & 4.26 & 0.000 & 0.18 \\
Advanced & 16.8 & 2.32 & & & & \\
Monolingual & 14.88 & 2.64 & & & & \\
\hline
\end{tabular}

Table 2(a). One-way ANOVA for fluency

\begin{tabular}{|l|l|l|l|l|l|}
\hline Source & df & Sum of Squares & Mean Square & F & Sig. \\
\hline Model & 1 & 469.84 & 469.84 & 16.31 & $<.0001$ \\
\hline Error & 119 & 3429.09 & 28.81 & & \\
\hline Corrected Total & 120 & 3898.94 & & & \\
\hline
\end{tabular}

Table 2(b). One-way ANOVA for elaboration

\begin{tabular}{|l|l|l|l|l|l|}
\hline Source & Df & Sum of Squares & Mean Square & F & Sig. \\
\hline Model & 1 & 143.12 & 143.12 & 12.37 & 0.0006 \\
\hline Error & 119 & 1365.31 & 11.57 & & \\
\hline Corrected Total & 120 & 1508.43 & & & \\
\hline
\end{tabular}

Table 2(c). One-way ANOVA for originality

\begin{tabular}{|l|l|l|l|l|l|}
\hline Source & Df & Sum of Squares & Mean Square & F & Sig. \\
\hline Model & 1 & 499.349054 & 499.349054 & 26.73 & $<.0001$ \\
\hline Error & 119 & 2204.702632 & 18.683921 & & \\
\hline Corrected Total & 120 & 2704.051685 & & & \\
\hline
\end{tabular}

Table 2(d). One-way ANOVA for flexibility

\begin{tabular}{|l|l|l|l|l|l|}
\hline Source & df & Sum of Squares & Mean Square & F & Sig. \\
\hline Model & 1 & 113.0509926 & 113.0509926 & 18.21 & $<.0001$ \\
\hline Error & 119 & 732.4289474 & 6.2070250 & & \\
\hline Corrected Total & 120 & 845.4799400 & & & \\
\hline
\end{tabular}




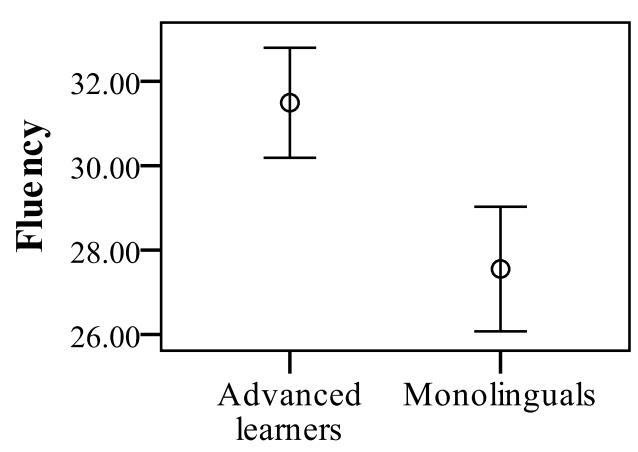

Language group

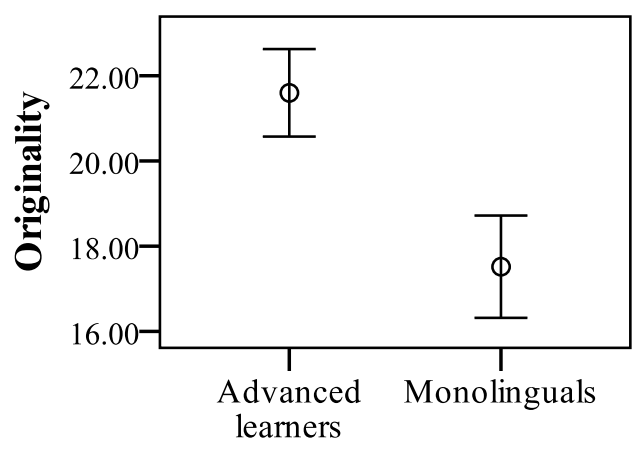

Language group

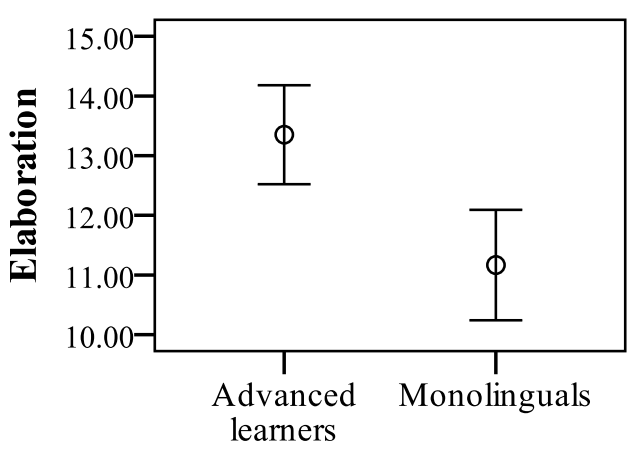

Language group

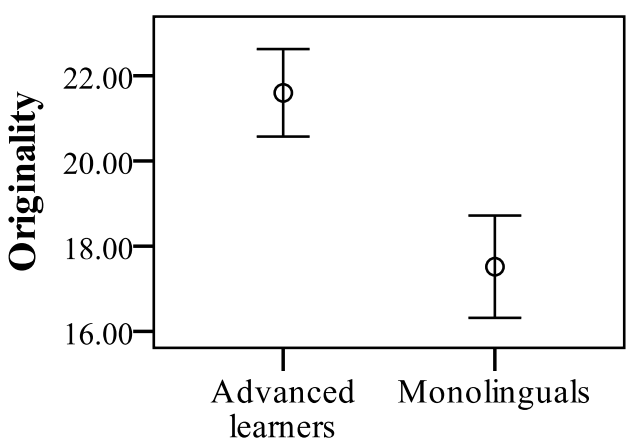

Language group

Figure1. Advanced foreign language learners' and monolinguals' performance on the TTCT measures of fluency, elaboration, originality and flexibility with error bars representing $95 \%$ confidence intervals. 